\title{
Comparative Study of Population Forecasting Methods
}

\author{
Dinesh W. Gawatre ${ }^{1}$,Mahesh H. Kandgule'2, Shankar D. Kharat ${ }^{2}$ \\ ${ }^{I}$ (Asst. professor, Civil Engineering Department, Sinhgad Academy of Eengineering,Pune) \\ ${ }_{2}^{2}$ (Student , Civil Engineering Department ,Sinhgad Academy of Eengineering,Pune)
}

\begin{abstract}
Precise calculation of population contributes in various aspects of providing fascilities to the public. In civil engineering, many structures like sewage treatment plant, water treatment plant, sizes of reservoires, storage tanks etc., are dependant upon the future population of the area for a specific design period.more or less the population than the actual population if taken it may hamper the project objective. Therefore one need to figure outaccurately the population of desired span of years. The report has been prepared to compare the various population forecasting methods.
\end{abstract}

Keywords: census, decade, incremental, logistic, population.

\section{Introduction}

India is the second most populous country in the world. And the rate of increase in population is also high. It indicates the need of precise calculation of the future population. For the successful design of the structures related to public use on a larger scale there is need to consider the most probable future population. Inaccurate or unsuitable methods of the population forecasting when used may result in increased cost of the construction or unable to satisfy the the project requirements. There are various methods used for forecasting the population each assuming various factors and assumptions. Each method gives the different value of future population. An attempt is made in this paper to compare the population of Pune district of year 2011 with the calculated population of the same year by five different methods. The populations of year 1971 to year 2001 were taken for calculation purpose. The population of Pune district consisted of populations of the villages and small towns even involved in the district. So no method is perfectly suitable for the conditions.

\section{Methods Of Population Forecasting}

Following are the commonly used methods for forecasting-

1) Arithmetic increase method

2) Geometric increase method

3) Incremental increase method

4) Simple graphical method

5) The logistic curve method

\section{1) Arithmetic increase method:-}

Average rate of increase in population is assumed to be constant from decade to decade in this method. Average increase per decade is found out from the previously available census data. The product of this amount obtained and number of decades for which the population is to be worked out is added to the present population of the subjected area to get the approximate population after $\mathrm{n}$ decades.

$\mathrm{Pn}=\mathrm{P}+\mathrm{nd}$

Where, $P n=$ future population after $\mathrm{n}$ decades

$\mathrm{P}=$ present population

$\mathrm{n}=$ number of decades

$\mathrm{d}=$ average increase per decade

\begin{tabular}{|l|l|}
\hline Year & Population in Lakh \\
\hline 1971 & 31.78 \\
\hline 1981 & 41.64 \\
\hline 1991 & 55.33 \\
\hline 2001 & 72.32 \\
\hline
\end{tabular}

\begin{tabular}{|l|l|l|l|}
\hline Sr.No & Year & Population in Lakh & Increase in Population \\
\hline 1 & 1971 & 31.78 & - \\
\hline 2 & 1981 & 41.64 & 09.86 \\
\hline 3 & 1991 & 55.33 & 13.69 \\
\hline 4 & 2001 & 72.32 & 16.99 \\
\hline \multicolumn{2}{|c|}{ Total } & 40.54 \\
\hline
\end{tabular}




\section{Solution:-}

For calculating the population of 2011,

No. of decades $(n)=\frac{2011-2001}{10}=1$

$\mathrm{P}_{0}=72.32$

Average increase in decade $(d)=\frac{40.54}{3}=13.5133$

Population at the end of $2011(\mathrm{Pn})=\mathrm{P}_{\mathrm{o}}+\mathrm{nd}$

$\mathrm{Pn}=72.32+(1 \times 13.5133)=85.8333$ lakh

\section{2) Geometric increase method}

Average percentage increase in population is assumed to be constant from decade to decade in this method. Averagepercentage increase per decade is found out from the previously available census data. By using the formula given below the future population is worked out.

$$
\mathrm{Pn}=P\left(1+\frac{r}{100}\right)^{n}
$$

Where, $\mathrm{Pn}=$ future population after $\mathrm{n}$ decades

$$
\begin{aligned}
& \mathrm{P}=\text { present population } \\
& \mathrm{n}=\text { number of decades } \\
& \mathrm{r}=\text { average percentage increase per decade }
\end{aligned}
$$

\begin{tabular}{|l|c|c|c|}
\hline Year & Population in Lakh & Increase in population & Percentage increase in population \\
\hline 1971 & 31.78 & - & - \\
\hline 1981 & 41.64 & 9.86 & $\frac{9.86 * 100}{31.78}=31.025$ \\
\hline 1991 & 55.33 & 13.69 & $\frac{13.69 * 100}{41.64}=32.877$ \\
\hline 2001 & 72.32 & 16.99 & $\frac{16.99 * 100}{55.33}=30.706$ \\
\hline Total & & 40.54 & $\frac{94.608}{3}$ \\
\hline \multicolumn{2}{|r|}{ Avg percentage decade } & $\frac{40.54}{3}=13.5133$ & $\frac{94.608}{3}=31.536$ \\
\hline
\end{tabular}

Average percentage increase $(r)=31.536 \%$

No. of decades $(\mathrm{n})=\frac{2011-2001}{10}=1$

$\mathrm{P}_{0}=72.32$

Population at the end of $2011(\mathrm{Pn})=P\left(1+\frac{r}{100}\right)^{n}$

$\mathrm{Pn}=72.32\left(1+\frac{31.536}{100}\right)^{1}$

$\mathrm{Pn}=95.1268 \mathrm{lakh}$

\section{3) Incremental increase method}

The advantages of both arithmetic increase method and geometrical increase method are included in this method. Average increase per decade is found out first of all and average percentage increase per decade is worked out as in arithmetic increase method and geometric increase method respectively. Future population is worked out from the equation given below.

$$
P n=P+n d+\frac{n(n+1)}{2} t
$$

Where, $\mathrm{Pn}=$ future population after $\mathrm{n}$ decades

$\mathrm{P}=$ present population

$\mathrm{n}=$ number of decades

$\mathrm{t}=$ average incremental increase per decade

$\mathrm{d}=$ average increase per decade

\begin{tabular}{|l|l|l|l|}
\hline Year & Population in Lakh & Increase in population & Increamental increase \\
\hline 1971 & 31.78 & - & - \\
\hline 1981 & 41.64 & 9.86 & - \\
\hline 1991 & 55.33 & 13.69 & +3.83 \\
\hline 2001 & 72.32 & 16.99 & +3.3 \\
\hline \multicolumn{2}{|l|}{ Total } & 40.54 & +7.13 \\
\hline \multicolumn{2}{|l|}{ Avg percentage decade } & $\frac{40.54}{3}=13.5133$ & $T=3.565$ \\
\hline
\end{tabular}


No. of decades $(n)=\frac{2011-2001}{10}=1$

$\mathrm{P}_{0}=72.32$

Population at the end of $2011(\mathrm{Pnn})=P+n d+\frac{n(n+1)}{2} t$

$(\mathrm{Pn})=72.32+1(13.5133)+\frac{1(1+1)}{2} 3.565$

$(\mathrm{Pn})=89.3983 \mathrm{lakh}$

\section{4) Simple graphical method}

Graph between the population and the corresponding year is plotted based on the available census data. The obtained curve is extended in the same manner to get the population of required year.it is the approximate method as the accuracy is dependent on the skill and experience of the person dragging the curve.

\begin{tabular}{|l|l|}
\hline Year & Population in Lakh \\
\hline 1971 & 31.78 \\
\hline 1981 & 41.64 \\
\hline 1991 & 55.33 \\
\hline 2001 & 72.32 \\
\hline
\end{tabular}

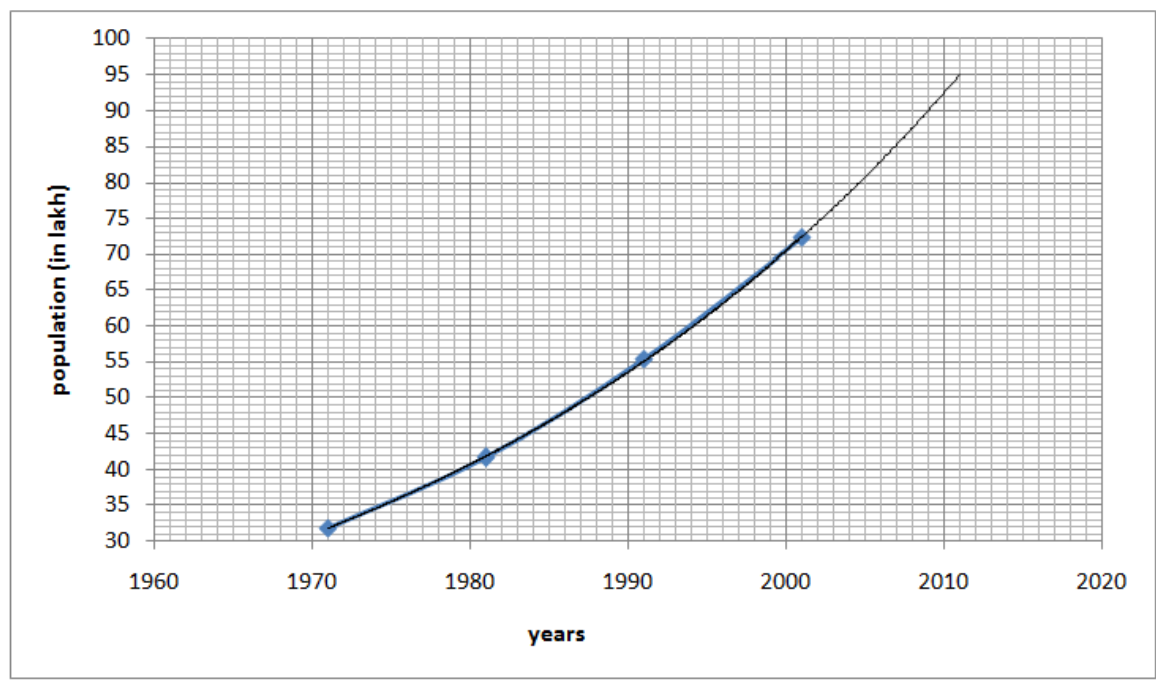

From graph, population at the end of $2011=95.00$ lakh

\section{5) The logistic curve method}

The growth is assumed to be a function of the time and follows some logical mathematical relationship the population tends to according to the logistic curve staring at low rate followed by high rate and then at lower rate towards the saturation limit.

\begin{tabular}{|l|l|}
\hline Year & Population in Lakh \\
\hline 1971 & 31.78 \\
\hline 1981 & 41.64 \\
\hline 1991 & 55.33 \\
\hline 2001 & 72.32 \\
\hline
\end{tabular}

$\mathrm{P} 0=41.64, \mathrm{t} 0=0$

$\mathrm{P} 1=55.33, \mathrm{t} 1=10$ years

$\mathrm{P} 2=72.32, \mathrm{t} 2=20$ years

The saturation population can be calculated by using equation

$\mathrm{P}_{\mathrm{s}}=\frac{2 \mathrm{P} 0 \mathrm{P} 1 \mathrm{P} 2-\left(\mathrm{P} 1^{2}(\mathrm{P} 0+\mathrm{P} 2)\right)}{\mathrm{P} 0 \mathrm{P} 2-\mathrm{P}^{2}}$

$\mathrm{Ps}=\frac{2 \times 41.64 \times 55.33 \times 72.32-\left(55.33^{2}(41.64+72.32)\right)}{41.64 \times 72.32-55.33^{2}}=312.6964$

We have, $m=\frac{P s-P 0}{P 0}=\frac{312.6964-41.64}{41.64}=6.5095$ 
$\mathrm{n}=\left(\frac{2.303}{t^{1}}\right) \log 10 \frac{\mathrm{P} 0(\mathrm{Ps}-\mathrm{P} 1)}{\mathrm{P} 1(\mathrm{Ps}-\mathrm{P} 0)}=\left(\frac{2.303}{10}\right) \log 10 \frac{41.64(312.6964-55.33)}{55.33(312.6964-41.64)}=-0.0336$

Population in 2011

$\mathrm{P}=\frac{\mathrm{Ps}}{1+\mathrm{mlog} \mathrm{e}^{-1}(\mathrm{n} . \mathrm{t})}=\frac{312.6964}{1+6.5095 \log \mathrm{e}^{-1}(-0.0336 \times 30)}=92.633 \mathrm{lakh}$

Percentage error in calculation

\begin{tabular}{|l|l|l|l|l|}
\hline Sr.no. & method & $\begin{array}{l}\text { Actual population } \\
\text { of 2011 }\end{array}$ & $\begin{array}{l}\text { Calculated } \\
\text { population of 2011 }\end{array}$ & $\begin{array}{l}\text { Percentage } \\
\text { error }\end{array}$ \\
\hline 1. & $\begin{array}{l}\text { Arithmetical increase } \\
\text { method }\end{array}$ & 94.29 & 85.8333 & 8.96 \\
\hline 2. & $\begin{array}{l}\text { Geometrical increase } \\
\text { method }\end{array}$ & 94.29 & 95.1268 & 0.88 \\
\hline 3. & $\begin{array}{l}\text { Incremental increase } \\
\text { method }\end{array}$ & 94.29 & 89.3983 & 5.18 \\
\hline 4. & Simple graphical method & 94.29 & 95.000 & 0.75 \\
\hline 5. & Logistic curve method & 94.29 & 92.633 & 1.756 \\
\hline
\end{tabular}

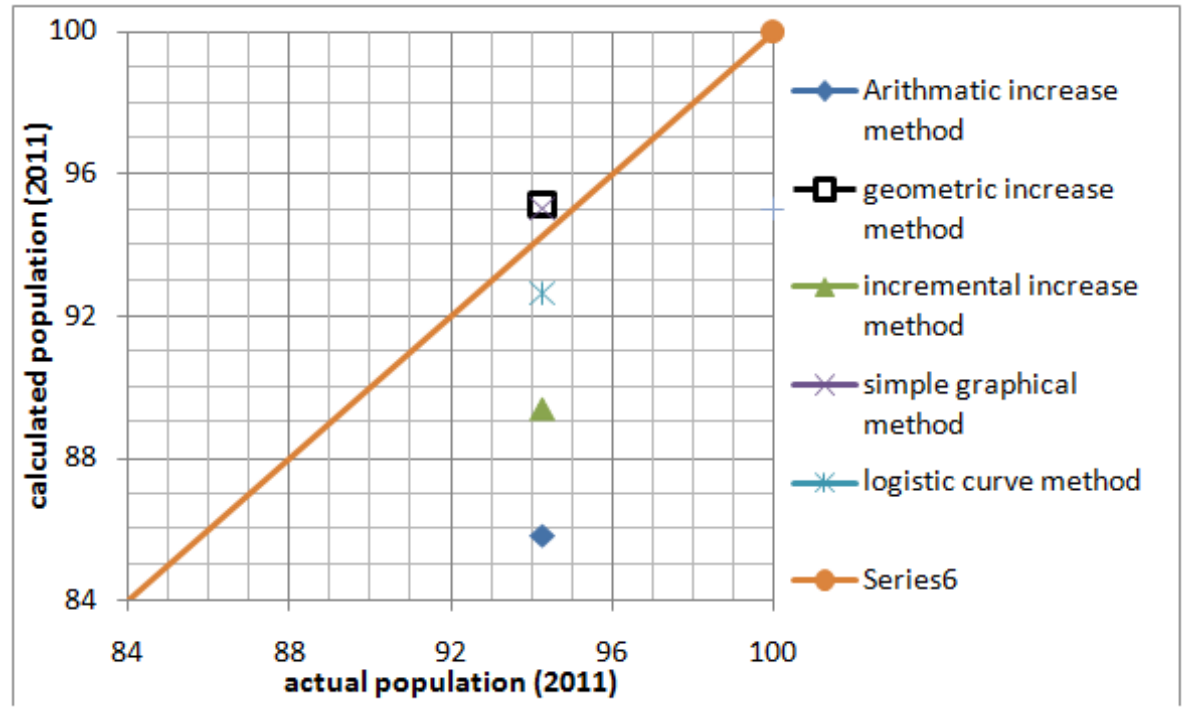

\section{Conclusion}

In the Light of the above, we can see that the geometric increase method is a simple realistic population model based on past information. This method tends to give a higher estimate than normal since it behaves exponentially. It more accurately describes the continuous and cumulative nature of population growth.

From the above graph and table it is concluded that the error of calculation of future population lies within the $\pm 10 \%$. The geometrical increase method is found to be the most accurate method calculation of the future population as simple graphical method is subjected to various errors.

\section{References}

[1] NPTEL IIT Kharagpur, web courses, module-5, lecture- 5, population forecasting.

[2] Population forecasting methods, a report on forecasting and estimating methods, U.S. department of transportation, federal highway of administration, bureau of public roads urban planning division.

[3] Punmia B.C., Arun K.J., water supply engineering.

[4] nptel.ac.in/courses/105105048/M5L5.pdf

[5] http://www.census2011.co.in/census/district/359-pune.html

[6] http://www.tongji.edu.cn/ yangdy/landuse/pfm/ch2.html

[7] http://www.censusindia.gov.in/2011census/dchb/2725_PART_B_DCHB_\%20PUNE.pdf

[8] archive.indianexpress.com/../770544/

[9] www.mpphed.gov.in/sman08.html 